\title{
Effects of radiofrequency electromagnetic radiation (RF-EMF) on honey bee queen development and mating success
}

\author{
Richard ODEMER $^{1 *}$, Franziska ODEMER ${ }^{1}$
}

${ }^{1}$ University of Hohenheim, Apicultural State Institute, 70593 Stuttgart, Germany

*Corresponding Author: richard.odemer@uni-hohenheim.de phone: +4915751302602

\section{ABSTRACT}

Mobile phones can be found almost everywhere across the globe, upholding a direct point-to-point connection between the device and the broadcast tower. The emission of radiofrequency electromagnetic radiation (RF-EMF) puts the surrounding environment inevitably into contact with this pollutant. We have therefore exposed honey bee queen 4 larvae to the radiation of a common mobile phone device (GSM) during all stages of their pre-adult development including pupation. After 14 days of exposure, hatching of adult queens was assessed and mating success after further 11 days, respectively. Moreover, full colonies were established of five of the untreated and four of the treated 8 queens to contrast population dynamics. We found that mobile phone radiation had 9 significantly reduced the hatching ratio but not the mating success. If treated queens 0 were successfully mated, colony development was not adversely affected. We provide 1 evidence that RF-EMF only acts detrimental within the sensitivity of pupal 2 development, once succeeded this point, no further impairment has manifested in 3 adulthood. Our results are discussed against the background of long-lasting 4 consequences for colony performance and the possible implication on periodic colony 25 losses.

7 Keywords: radiofrequency electromagnetic radiation (RF-EMF); honey bee queen 8 development; mating success; Apis mellifera; mobile phone devices; colony collapse disorder (CCD) 
- Chronic RF-EMF exposure significantly reduced hatching of honey bee queens

- Mortalities occurred during pupation, not at the larval stages

- Mating success was not adversely affected by the irradiation

- After the exposure, surviving queens were able to establish intact colonies

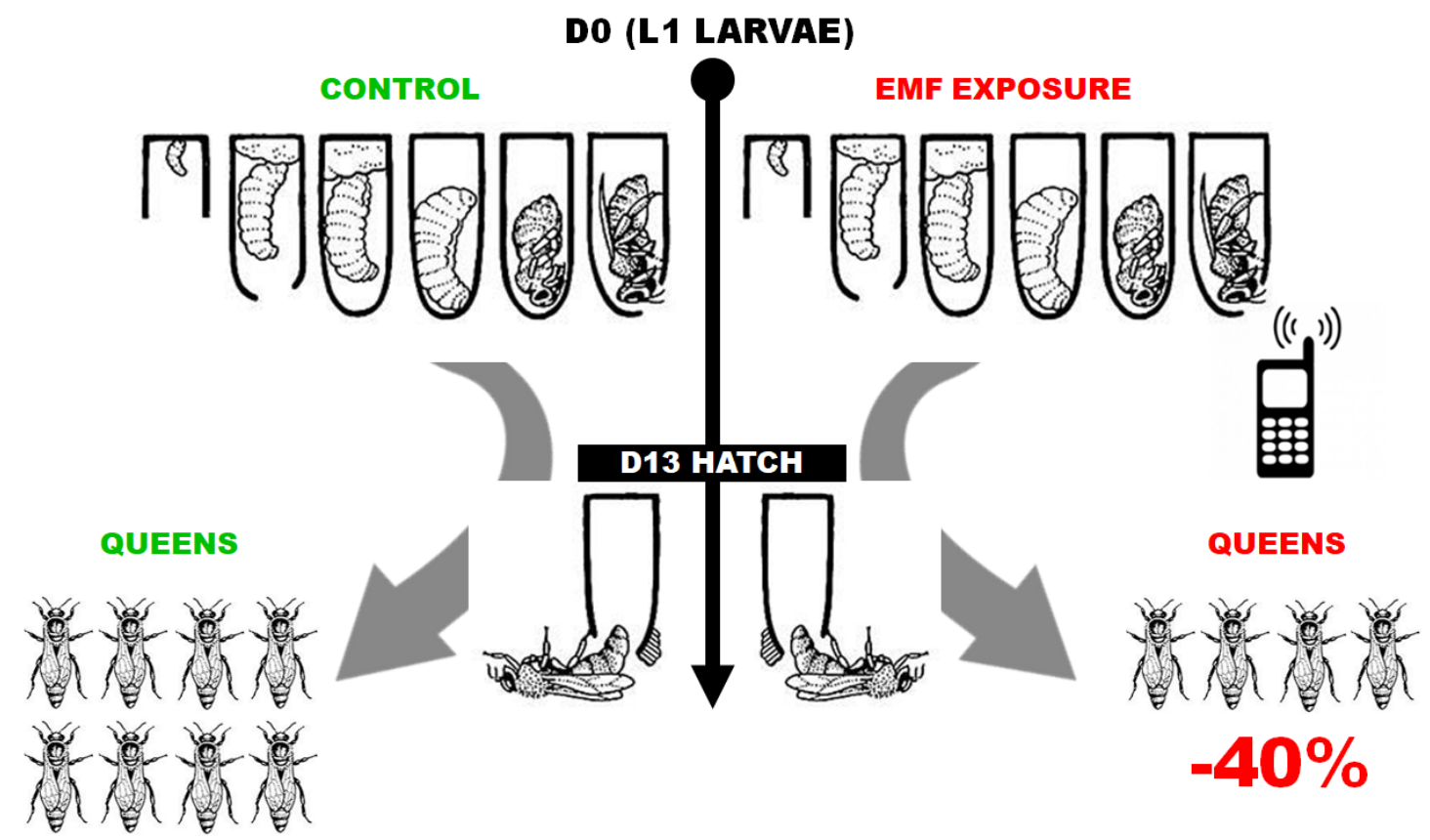




\section{INTRODUCTION}

46 The modern world turns around technological achievements and it is simply not

47 possible to imagine our everyday life without them. With an estimated 6.9 billion

48 subscriptions globally, mobile phone devices such as smart phones have established

49 their position in our society (WHO, 2014). In many countries, cell phones are important

50 tools not only for communication but also for bank transfers, newscast, social media and numerous other conveniences with an increasing tendency. Provided that this market will be further growing in the future, concerns are rising about the emission of radiofrequency electromagnetic fields (RF-EMF) from these devices and their broadcasting network, i.e. antennas and base stations, perceived as environmental pollution (Balmori 2015).

Radiofrequency waves are electromagnetic fields, and unlike ionizing radiation such as $\mathrm{X}$-rays or gamma rays, they can neither break chemical bonds nor cause ionization in the living tissue (Genuis \& Lipp 2012). They are usually ranging from $30 \mathrm{kHz}-300 \mathrm{GHz}$ with cell phones operating mainly between $800 \mathrm{MHz}$ and $3 \mathrm{GHz}$, pulsed at low frequencies (Hardell 2017). As a consequence, they are often strictly forbidden in medical facilities and on airplanes, as the radiofrequency signals may interfere with certain electro-medical devices and navigation systems.

In the last decade field and laboratory studies have furthermore demonstrated that RFEMF exposure is of ecological relevance. The radiation may have an impact on surrounding flora as well as vertebrate and invertebrate organisms (Cucurachi et al. 2013). Effects have manifested in different ways and some of them are a cause of concern. A large scale monitoring study ( $>10$ years) revealed that in trees, a closer range to phone masts resulted in significant damages in the side facing the mast in contrast to the opposite side (Waldmann-Selsam et al. 2016) whereas Roux et al. (2006, 2008) found exposed tomato plants to show similar consequences when wounded, trimmed or burnt. In chicken eggs, Batellier et al. 2008 found an increased mortality when exposed to cell phone radiation over the entire incubation period. Very similar to previous study results from Bastide et al. (2001) and Grigoryev (2003), this 
developmental stage seems to be particularly vulnerable for non-thermal radiation. A proportional relationship between the intensity of the electromagnetic field and the negative effects, however, could not be established (Batellier et al. 2008).

In fruit flies, reproduction and reproductive organs were also significantly affected by mobile phone radiation (Panagopoulos et al. 2004, Panagopoulos 2012) unlike to the findings of Weisbrot et al. (2003) where a beneficial effect on the reproductive success was reported. In their study, the number of offspring increased by up to $50 \%$ compared to control, demonstrating controversial outcomes. Studies in insects have shown that reproduction cycles and change of generations are quick, making this test system suitable for the detection of possible consequences of RF-EMF exposure. Important biological endpoints such as fertility, reproduction, behavior and development are rather easy to implement, especially in a laboratory setting.

Besides the fruit fly as model organism, special ecological relevance is outlined by pollinators, in particular by the honey bee Apis mellifera. They provide critical pollination services valued at over $\$ 200$ billion worldwide (Lautenbach et al. 2012), representing $9.5 \%$ of the total human food production (Gallai et al. 2009). However, bees have suffered periodic losses within the last century, and in the US a phenomenon called colony collapse disorder (CCD) made headlines in the first decade of the new millennium (vanEngelsdorp et al. 2009). Several causative factors have been outlined in the past, among others, pathogens, malnutrition, management, and pesticides have been narrowly focused as main culprits (Steinhauer et al. 2018).

Many other factors were also considered to have an impact on honey bee health, however with a rather insignificant regard. A few to name are air pollution (Girling et al., 2013; McFrederick et al., 2008), nanomaterials (Milivojevic et al., 2015), solar radiation (Ferrari, 2014), robbing insects (Core et al., 2012) and global warming (Le Conte \& Navajas, 2008). Worthy of mention, in 2007 a story in an UK newspaper brought to the fore that CCD can be linked to RF-EMF with drastic consequences for bee behavior and homing success (Kimmel et al. 2007; Carreck, 2014). Subsequent studies seem to provide supporting evidence of impaired behavior (Favre, 2011) and affected homing ability (Ferrari, 2014), bearing a potential risk to other bee species such 
104 as bumblebees (Bombus terrestris), when interacting with floral electric fields and

105 electric field sensing as important sensory modality (Clarke et al., 2013).

106 However, there are far too few scientific publications to draw a clear conclusion in

107 regard if and to which extent mobile phone radiation represents a real threat to honey

108 bees. A current review actually goes as far as stating that all examined studies were

109 characterized by substantial shortcomings which were sometimes even admitted by their

110 authors upfront (Verschaeve, 2014).

111 For a honey bee colony, health and productivity is directly linked to its queen. She

112 represents the growth potential expressed as productivity, being the only egg layer in

113 the collective and therefore responsible for a positive turnover of workers to increase in

114 size at the beginning of each bee season (Moore et al. 2015). In an US survey of winter

115 colony losses, the fourth most important factor identified was due to queen failure

116 (vanEngelsdorp et al., 2008). Given the importance of this individual, our experiments

117 therefore strictly focused on ontogenetic development and further mating success of

118 young queens. We have created a worst case scenario, where mobile phone radiation

119 was adopted by natural means of human exposure. To our knowledge this is the first

120 study that analyzes the effect of a chronic application of mobile phone radiation on

121 honey bee queens. We wanted to prove (i) if under field conditions and good apicultural

122 practice the radiation has any effect at all and to what extent, in addition (ii) we wanted

123 to follow queens which developed under chronic RF-EMF exposure to assess potential

124 risks for the bee colony. 


\section{MATERIALS \& METHODS}

\subsection{Field sites and weather conditions}

131 The field sites were located near the Apicultural State Institute in Stuttgart-Hohenheim, 132 Southern Germany $\left(48^{\circ} 42^{\prime} 31.8^{\prime \prime} \mathrm{N} 9^{\circ} 12^{\prime} 38.2^{\prime \prime E}\right)$. At the time present, natural food 133 sources consisted mainly of nectar from diverse local flora such as Taraxacum 134 officinale, Rubus section, Tilia spp. and others. The average temperature during the 135 experiment ranged from 15.2 to $20.1{ }^{\circ} \mathrm{C}$ with a precipitation of 90 to $45 \mathrm{~L} / \mathrm{m}^{2}$. Overall, 136 good weather conditions prevailed for both, mating and foraging (DWD 2018).

\section{$137 \quad 2.2 \quad$ Experimental setup}

138 This study was performed from May until August in 2018 with healthy queenright

139 colonies from the stock of our apiary. Two replications were employed simultaneously, 140 consisting of two collector colonies: Rep1 (Control1 + EMF1) and Rep2 $=($ Control2 + 141 EMF2). For both approaches, one brood frame with almost fully covered areas of sealed 142 brood and attached bees from eight random colonies were taken out on D-9 and placed 143 in a new ten-frame box, respectively. This box was supplied with two frames of food, as 144 well as a second box on top with ten food frames to ensure sustenance and sufficient 145 room for the hatching bees. Nine days after this procedure (D0), the hive was inspected, 146 and where appropriate, supersedure cells were removed to prevent the introduction of a 147 young queen. Further, 18 frames then were split homogeneously but random into two 148 boxes with nine frames each, complemented with a grafting frame in the center. L1 149 larvae from a selected colony were grafted and introduced, respectively. Again, grafting 150 of the larvae was randomized by using both sides of the brood comb (A and B). Per 151 replication, 26 larvae $(13 \mathrm{~A}, 13 \mathrm{~B})$ were assigned to each treatment, i.e. control and EMF.

153 The two boxes then were placed at a different location in approximately $3 \mathrm{~km}$ distance 154 to prevent worker bees to return to their original position. Subsequently, at different 155 intervals, assessments were performed to check the no. of accepted larvae after grafting 156 (D1), to protect the capped cells before hatching (D10), to check the hatching rate (D13) 157 and the mating success (D24). After the young queens have hatched, they were 
158 transferred to mating units consisting of one of the former brood frames with 159 approximately 1,000 bees attached and one food comb.

160 Successful mating was confirmed on D24 by the presence of eggs, young larvae and 161 capped brood and queens from each treatment (five from the control, four from the 162 treatment) were re-accommodated in new 10-frame boxes to develop into full colonies. 163 After approximately twelve weeks (D88), a colony assessment was performed to record 164 the number of bees and brood. See Fig. 1 for a detailed timeline.

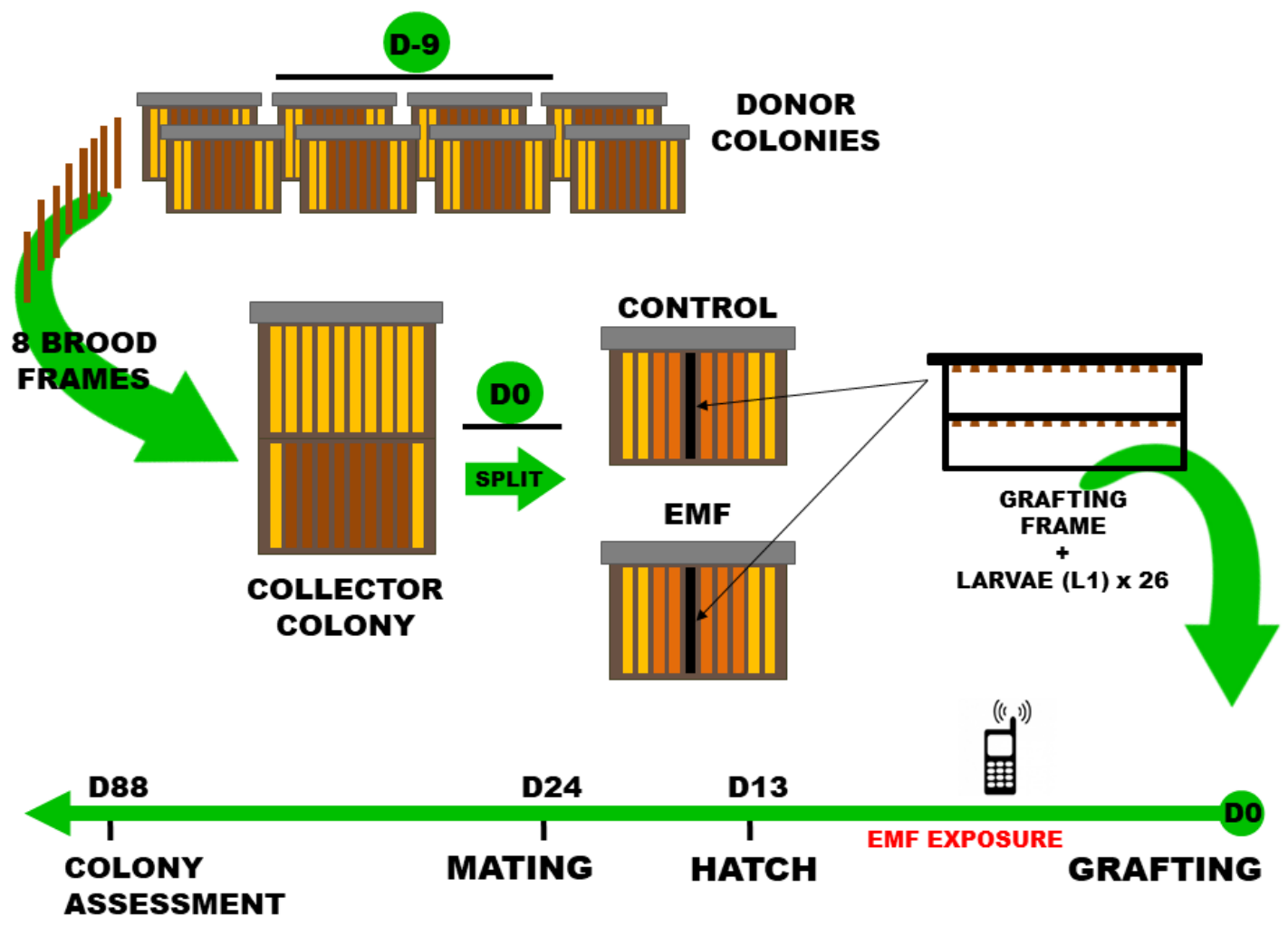

166 [Fig. 1 Timeline of the experiment. At D-9, eight brood frames with attached bees were taken out from 167 respective donor colonies and placed in one collector colony. At D0, supersedure cells were removed and 168 the collector colony was split in two sub-colonies. In addition, a grafting frame with L1 larvae was 169 inserted. RF-EMF exposure lasted until D13, when queens were about to hatch. Young queens were 170 subsequently inserted into mating units where mating success was checked at D24. Successfully mated 171 queens with one frame of approximately 1,000 bees were relocated into new boxes where they were able 172 to establish a new colony. Finally, at D88 the condition of these colonies was assessed.] 


\subsection{EMF treatment}

174 Queen larvae/pupae were treated with a mobile phone (AEG M1220, GSM quad band:

$175800 / 900 / 1800 / 1900 \mathrm{MHz}$, China) attached to the grafting frame holding 26 queen cups

176 (Nicot, NICOTPLAST SAS, Maisod, France), this device was turned off in the control

177 group for sham exposure. To ensure power supply, the phone was equipped with a

178 power bank (PLOCHY 24,000 mAh Solar, China), the battery status was frequently

179 checked. After the larvae were grafted into the cups by using an appropriate tool, 15

180 telephone calls with a two minute duration were applied daily for a total of two weeks

181 (non-modulated emission) at random. The radiation was measured three times in three

182 different distances to the mobile phone with a fixed instrument illustrated in Fig. 2 (Pyle

183 PMD74, Calibration: $2450 \mathrm{MHz}$, measurement range: $0-15 \mathrm{~mW} / \mathrm{cm}^{2}$, China) to verify

184 an adequate EMF output.

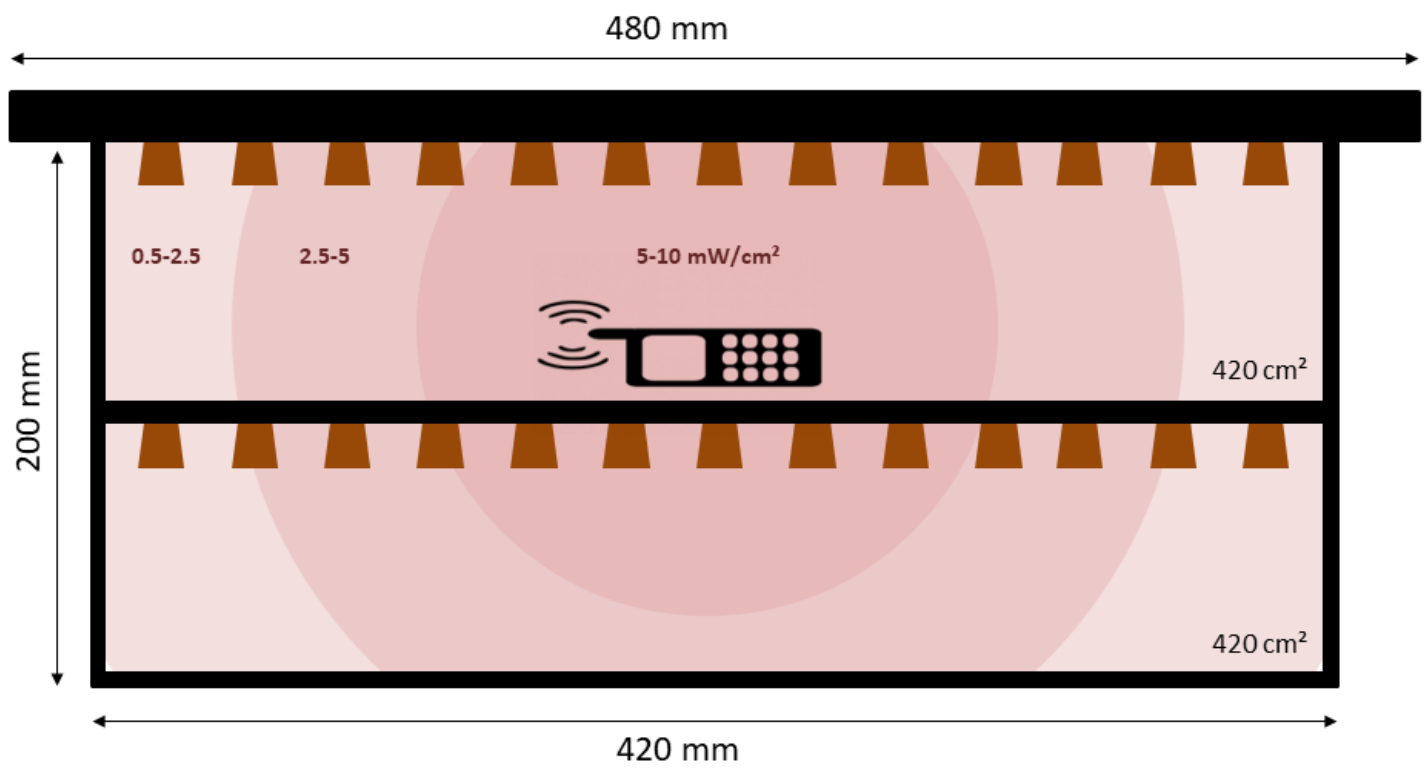

[Fig. 2 Grafting frame placed in the EMF treatment colony containing 26 queen cups. The mobile phone device was attached in the center of the frame, its radiation intensity is indicated with the differently colored sections in the illustration (dark $>$ light) ]

\subsection{Colony assessment}

The amount of bees and brood cells (open and sealed) were estimated with the Liebefeld Method (Imdorf et al., 1987), which is a feasible tool to provide accurate and reliable evaluation of colony strength (measuring error $+/-10 \%$ ). Care was taken that all 
193 colonies were evaluated by the same person to minimize variation and colony assessment was conducted in the morning before bee flight.

\section{$195 \quad 2.5 \quad$ Statistical analysis}

196 We evaluated the mortality data with a Kaplan-Meier-Survival analysis. Survivorship

197 between control and treatment was compared pairwise and tested for significance with a

198 Log-Rank Tests (Cox-Mantel). Individuals collected at the end of the experiment were

199 considered censored, as were those observed but not collected on the final day.

200 Furthermore, larvae that disappeared during the experiment were considered dead on the

201 last day they were seen. Both treatment groups and the two replicates $(\operatorname{Rep} 1=$ Control1

$202+$ EMF1; Rep2= Control2 + EMF2) were additionally compared with a Cox 203 proportional hazards model to determine the hazard ratio (HR). Possible inter-colony 204 effects were evaluated as covariate to justify pooling data of the same treatments. The 205 estimated number of bees and brood cells were checked with a Shapiro-Wilk test for 206 normal distribution. If data was normal, a one-way ANOVA was performed on the two 207 experimental groups, respectively. For all tests RStudio (R Core Team, 2018) and 208 significance level of $\alpha=0.05$ was used.

\section{RESULTS}

\subsection{Honey bee queen survival}

212 The Kaplan-Meier-Survival analysis of both groups showed a significant difference

213 indicating a higher mortality of the EMF treated bees when compared to the control 214 group ( $\mathrm{p}=0.0054$ ) (Fig. 3). In addition, a Cox proportional hazards model was applied to 215 determine the hazard ratio (HR) displayed as forest plot (Fig. 4). With a HR of 2.3 the

216 EMF treated queens had a significantly increased risk of dying when compared to the 217 control $(\mathrm{p}=0.003)$. Moreover, the two replicates (Rep1 and Rep2) were compared as 218 covariate to display possible inter-colony effects. However, with a HR of 1.7 queens in 219 Rep2 did not have a higher risk of dying when compared to Rep1 ( $p=0.062)$, therefore 220 data of both replicates were pooled. 


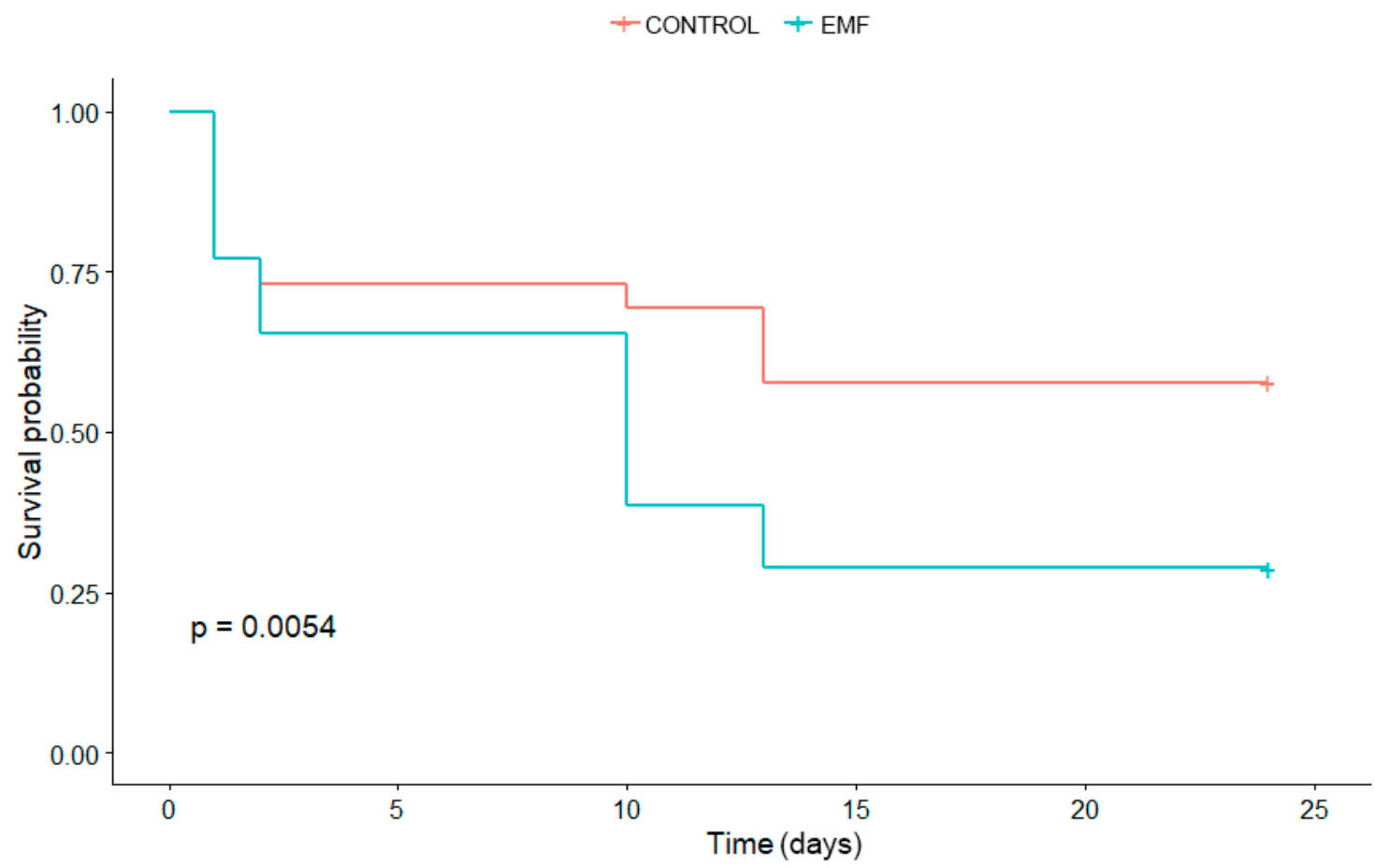

222 [Fig. 3 Both groups were compared with a Kaplan-Meier-Survival analysis. A post-hoc Log-Rank test

223 (Cox-Mantel) revealed a significant higher mortality in the EMF treatment when compared to the control

224 (Log-Rank $\mathrm{p}=0.0054$ ), where a significant decrease of individuals occurred during the pupation phase of the experiment (see also Fig. 5)]

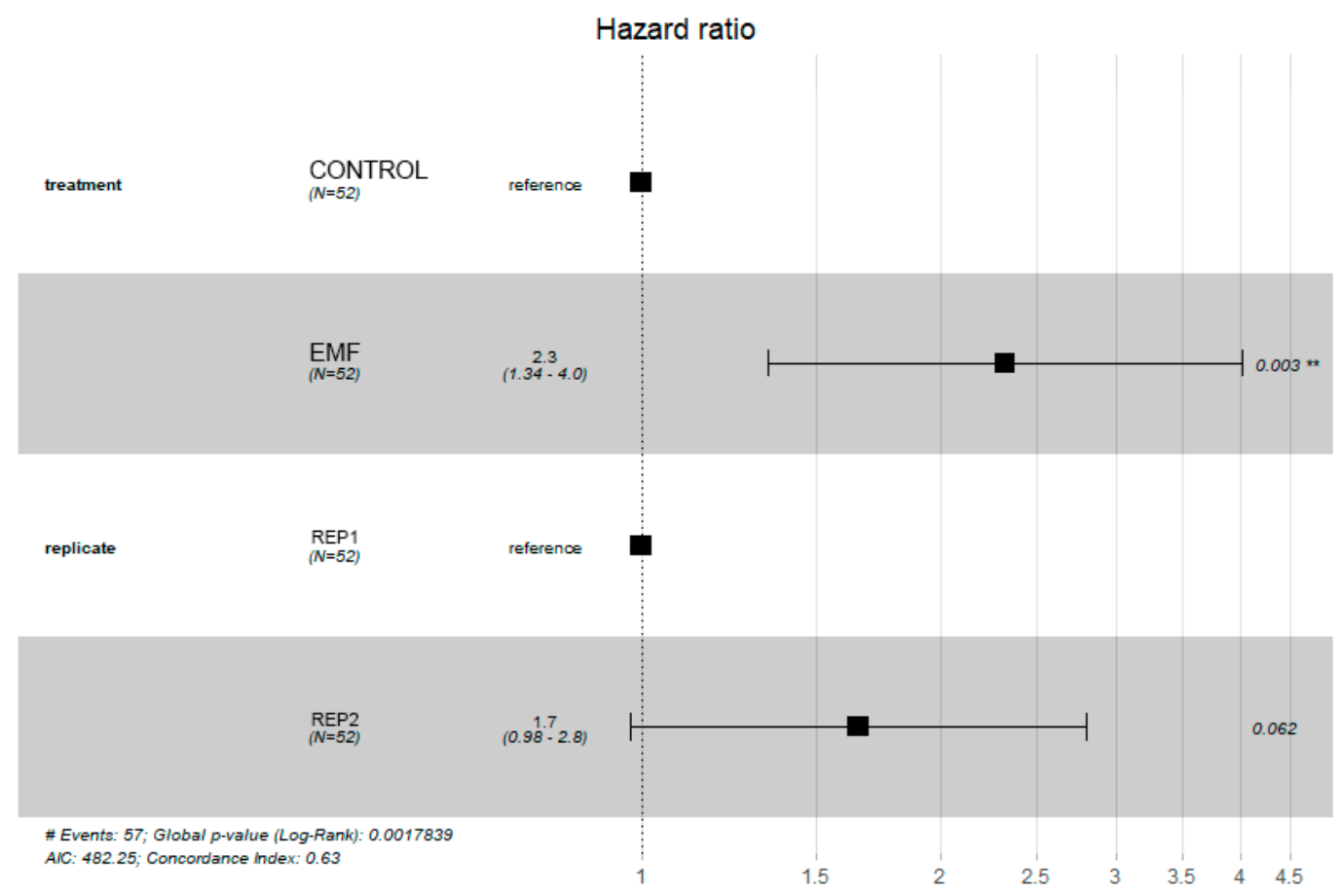


229 [Fig. 4 Both treatment groups and the two replicates (Rep1 and Rep2) were additionally compared with a

230 Cox proportional hazards model to determine the hazard ratio (HR) displayed as forest plot. With a HR of

2312.3 the EMF treated queens had a significantly increased risk of dying when compared to the control

$232(\mathrm{p}=0.003)$. And with a HR of 1.7 queens in Rep2 did not have a higher risk of dying when compared to

$233 \operatorname{Rep} 1(\mathrm{p}=0.062)]$

$234 \quad 3.2$ Hatching and mating success

235 The acceptance rate of grafted larvae on D1 was $76.9 \%$ and identical in both 236 treatments. As shown in Fig. 3, a significant decrease of individuals in the EMF 237 treatment occurred during the pupation phase of the experiment. At D10, queen cells 238 were protected with a cage to prevent hatching queens from killing each other. We 239 observed a ratio of 73.1 (control) to $65.4 \%$ (treatment) at this stage compared to the 240 initially grafted cells. The hatch of adult queens at D13 revealed a significant decrease 241 of formerly treated queens during pupation with a proportion of $69.2 \%$ in the control to $24238.5 \%$ in the treatment, levelling out with a similar decrease of both groups at the 243 assessment of mating success at D24 (control $57.7 \%$, treatment $28.8 \%$ ) (for statistical 244 evaluations see also Fig. 3).

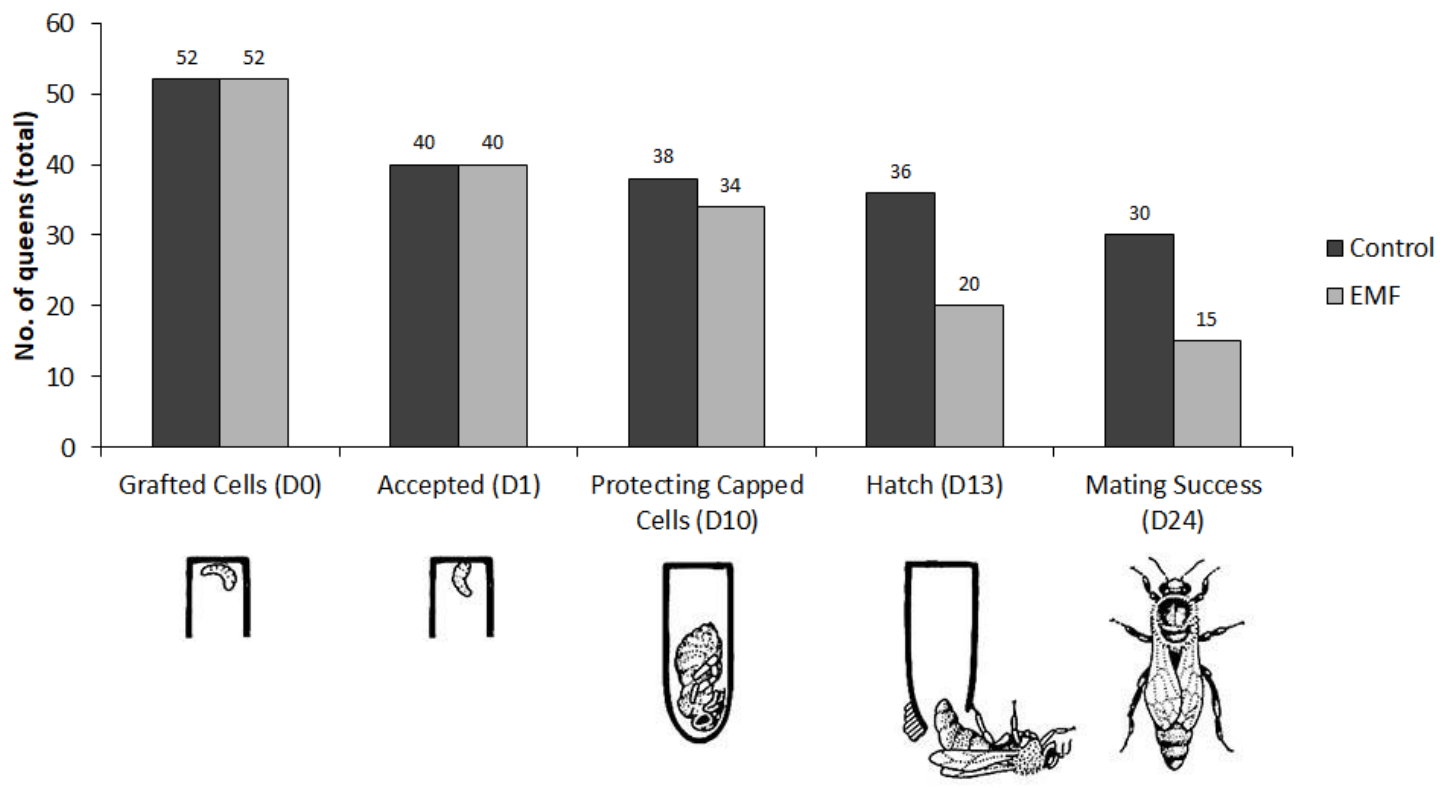

246 [Fig. 5 Total number of L1 larvae grafted and followed through their ontogenetic development from pupa

247 to adult. In the EMF treatment a significant decrease of individuals came into effect within the pupation 248 phase of the experiment (see also Fig. 3). Illustrations after Gullan \& Cranston 2014] 


\subsection{Colony assessment}

251 The population of bees and brood cells was estimated at D88. The results are shown in 252 Fig. 6A for the number of bees and in Fig. 6B for the number of brood cells. We 253 compared the two treatment groups with a one-way ANOVA but could not see 254 significant differences for the number of bees $(\mathrm{p}=0.688)$ or the amount of brood cells $255 \quad(\mathrm{p}=0.768)$.

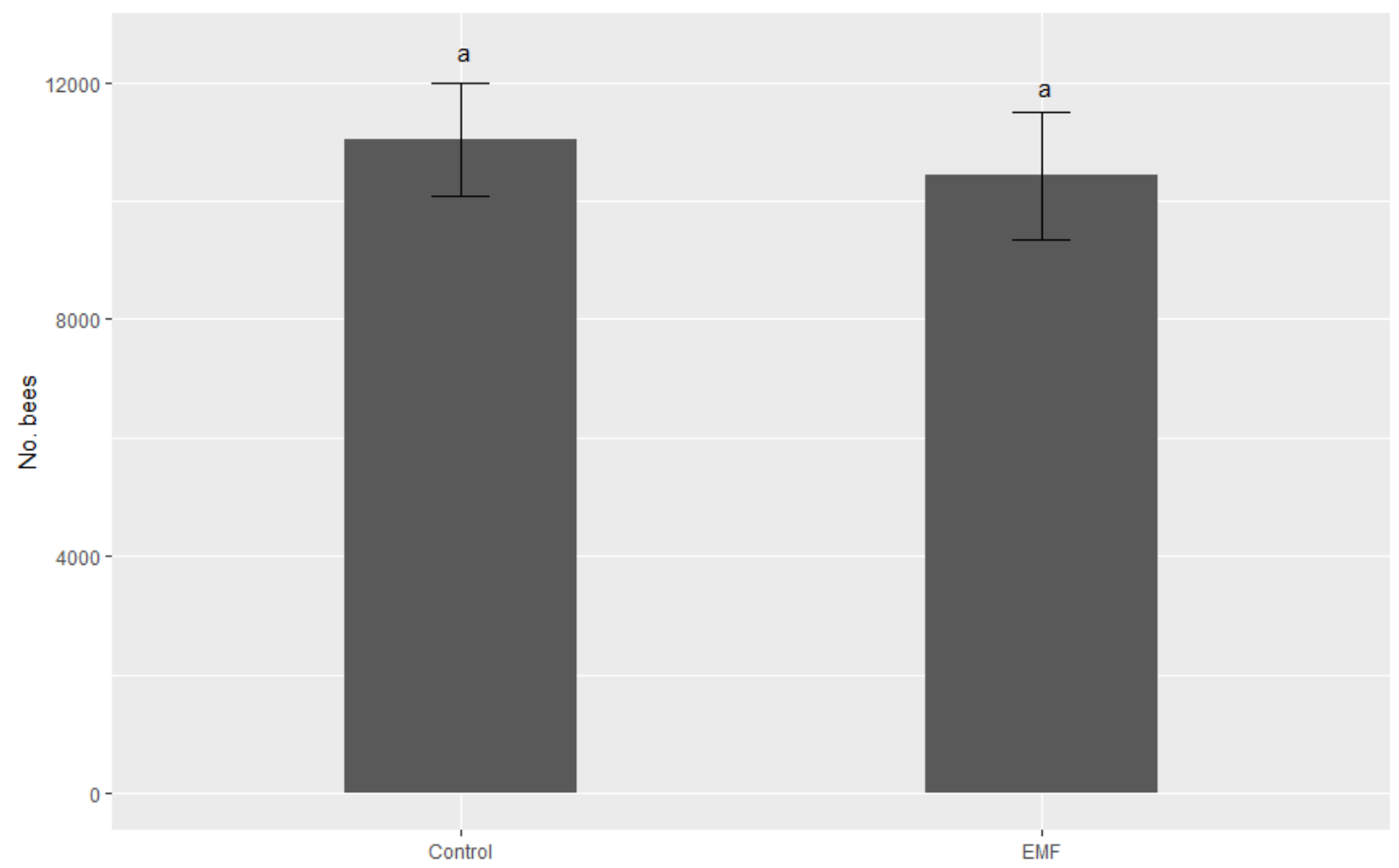

257 [Fig. 6A Number of bees estimated at D88 in the colonies of the control $(n=5)$ and of the EMF treatment $258(\mathrm{n}=4)$. Same letters indicate no statistically significantly differences $(\mathrm{p}=0.688$, ANOVA).] 


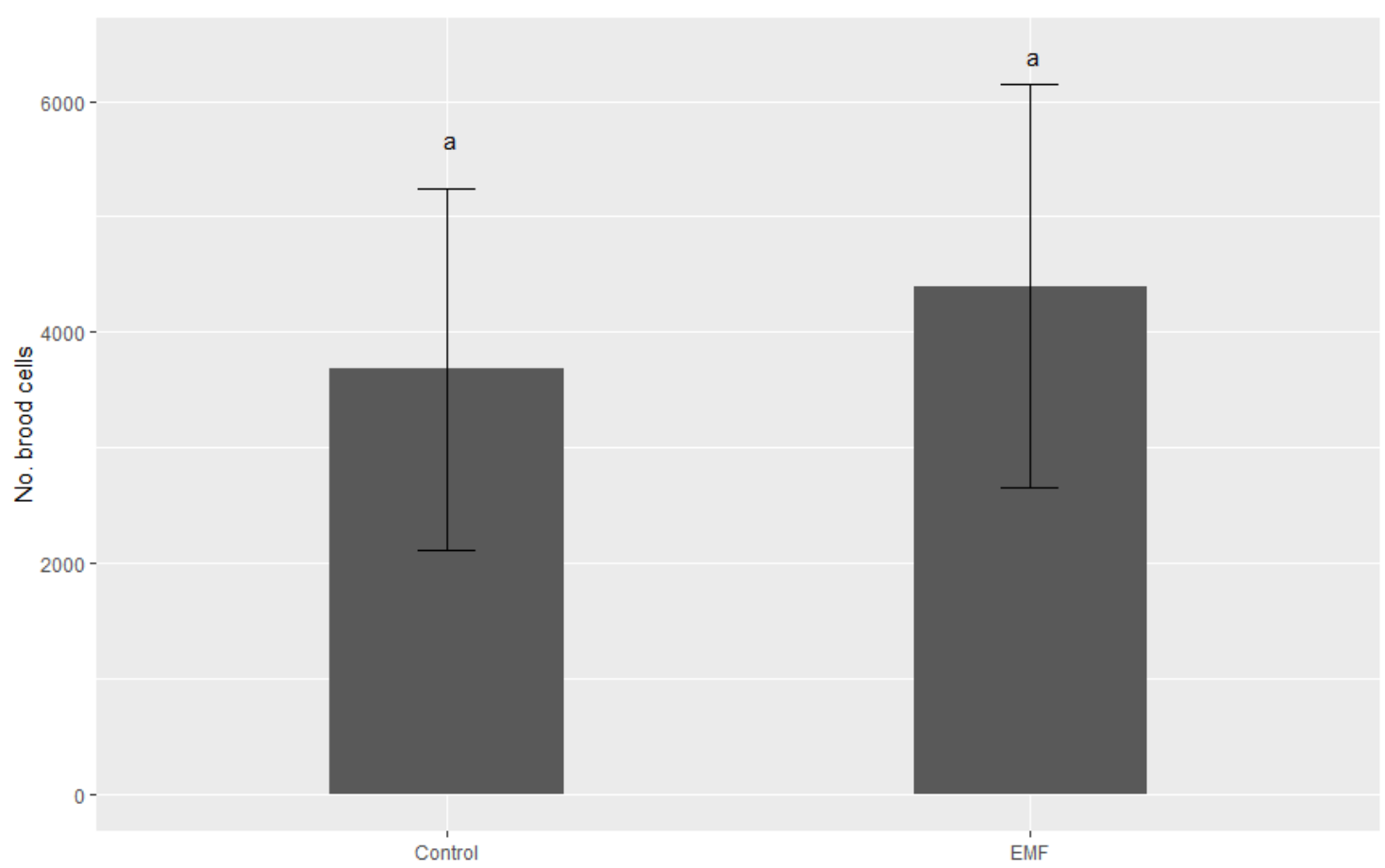

260 [Fig. 6B Number of brood cells estimated at D88 in the colonies of the control $(n=5)$ and of the EMF

261 treatment $(\mathrm{n}=4)$. Same letters indicate no statistically significantly differences ( $\mathrm{p}=0.768$, ANOVA).] 


\section{DISCUSSION}

266 The emission of radiofrequency electromagnetic fields (RF-EMF) and their negative

267 effects towards honey bee health has been controversially discussed in the past (Carreck

268 2014; Verschaeve 2014; Panagopoulos et al. 2016). Here, we could demonstrate for the

269 first time that RF-EMF exposure has significantly affected ontogenetic queen

270 development under field conditions. We observed an increased mortality during

271 pupation resulting in a reduced hatching rate of the later queens. This is in line with a

272 reduced reproductive capacity found in fruit flies (Drosophila melanogaster)

273 (Panagopoulos et al. 2004, Margaritis et al. 2014), where a linear decrease of fecundity

274 was reported with the frequency of exposure (Panagopoulos and Margaritis 2010). This

275 decrease was further associated with the distance to the mobile phone device showing

276 the strongest effects at $<10 \mathrm{~cm}$ (Panagopoulos et al. 2010). In our setup, the most

277 distant queen cups were approximately $21 \mathrm{~cm}$ away from the radiation source and we

278 therefore assume that for all larvae a worst case scenario came into effect. In addition,

279 the impairment of fruit flies seemingly depended on field intensity (Panagopoulos et al.

280 2007) not only reducing the offspring but also the ovarian size of the exposed subjects

281 (Panagopoulos 2012).

282 At present, only a few studies have investigated the influence of irradiation on insect 283 development. As an example, larvae and pupae of the dried fruit beetle (Carpophilus 284 hemipterus) and the yellow fever mosquito (Aedes aegypti) were exposed to Gamma 285 radiation (ionizing radiation). The radiotherapy did not cause acute death in larvae but 286 decreased pupation significantly, no effects however could be observed when either 287 young or old pupae were exposed (Johnson 1987, Akter \& Khan 2014). It seems likely 288 that RF-EMF had a similar effect in our study, as larval mortality was not elevated. 289 However, this should be further underpinned by exposing larvae and pupae separately. 290 Moreover, Vilić et al. (2017) found honey bee worker larvae significantly affected when 291 exposed to modulated but not to non-modulated RF-EMF radiation, resulting in DNA 292 damage and further corroborating our hypothesis as we only have used non-modulated 293 fields. 
294 In addition, we could show that mating success remained unaffected suggesting that navigation and the possible disruption of magnetoreception came not into effect or was

296 at least not long-lasting (Vácha et al. 2009). Interestingly, we provide evidence that

297 developing honey bee queens once they have survived RF-EMF exposure seem to retain

298 the ability to establish an intact colony. This is indicated by similarly strong numbers of

299 bees and the amount of brood in both our treatment groups with the absence of any

300 signs of impairment (e.g. patchy brood pattern). As a further critical step of colony

301 survival however, overwintering should also be assessed to elucidate possible long term effects from the irradiation (Smart et al. 2016).

303 The social entity as a whole is able to buffer environmental stressor of various kinds as an expression of social resilience (Straub et al. 2015). Worker bees are nursing eggs and feeding larvae of different casts in their social state, potentially contributing to this mechanism. Here we focused on the development of individual queens from larvae to adult, however, the outcome of our study could also be influenced by the condition of the collector colonies that we have created but not further assessed. Eggs, larvae and pupae are very sensitive stages of development and intensive care is taken to supply their substantial needs in terms of nutrition and environmental conditions, i.e.

311 maintaining a constant temperature and humidity (Wang et al. 2015, Eouzan et al.

312 2018). RF-EMF radiation is known to affect bees behavior in different ways (Favre

313 2011, Ferrari 2014), which makes it plausible that brood care could also be adversely

314 affected. This important factor should be further investigated and included in future

315 experiments.

316 With an increasing number of mobile phone devices and as a consequence of good 317 accessibility a higher density of phone masts, not only urban but also rural areas in 318 particular are more and more exposed to irradiation (Balmori 2009). A measurement of 319 RF-EMF intensities across different European cities revealed maximum radiation values 320 ranging from 0.84 to $0.59 \mathrm{~V} / \mathrm{m}$ corresponding to 92.33 and $187.16 \mathrm{nW} / \mathrm{cm}^{2}$ (Urbinello et 321 al. 2014a), respectively, with a maximum value of $127 \mathrm{nW} / \mathrm{cm}^{2}$ in public transport

322 (Sagar et al. 2016). In contrast, the power flux density measured in our study seemed to 323 be way beyond these values, demonstrating that the intermittent stress on the test 324 subject(s) can be many fold higher than average levels measured in the surroundings, 
emitted from generators or found in agglomerations. Our findings confirm that there is a

326 high variability in mobile phone emission (Frei et al. 2009), representing an important

327 feature in terms of bioactivity towards living organism's defense against environmental 328 stressors (Panagopoulos et al. 2015). The authors therefore suggest not using simulated

329 but real mobile phone emissions in an experimental setup, which we have considered. In

330 addition, we have tried to apply a human exposure scenario in terms of average number

331 of calls and average call duration performed with mobile phone devices. The mobile call

332 duration reported by the German Federal Network Agency (2011) was 2.5 min per day,

333 in Shum et al. (2011) ranging from $2.1 \mathrm{~min}$ (self-reports) to $2.8 \mathrm{~min}$ (billing records)

334 and $<2 \mathrm{~min}$ in Friebel \& Seabright (2011). Further, the average number of calls per day 335 ranging from 4.1 (Shum et al. 2011) to 5 per day in adults (Lenhart 2010). In contrast, 336 an average of $33.1 \mathrm{~min}$ was reported for total mobile phone call duration from 337 undergraduate college students per day in the US (Roberts et al. 2014). We therefore 338 decided to employ 2 min per call and 15 calls per day resulting in 30 min exposure per 339 day in our experiment, representing a realistic human exposure.

340 Different exposure scenarios were applied in honey bees and a broad range of effects 341 are reported (Cucurachi et al. 2013). Some studies even claimed with RF-EMF to have 342 found the major cause for CCD (Carreck 2014). However, many of these studies had 343 substantial deficits such as a very low sample size (Sharma \& Kumar 2010), 344 intransparent methods (Sahib 2011, Kumar et al. 2011, Dalio 2015) or were even 345 preliminary and did not undergo peer-review (Kimmel et al. 2007). Therefore, findings 346 of this quality were generally not considered reliable in their contribution to colony 347 losses and are far from conclusive (Carreck 2014). To achieve a broader understanding 348 how RF-EMF potentially influences the honey bee superorganism, it is mandatory to 349 emphasize the conditions under which the study was conducted, particularly the level 350 and duration of exposure, in the presence of the relevant environmental situation 351 (Verschaeve 2014).

352 As a trend of the last decades, beekeeping became famous with the life style of 353 townsmen all across the globe (Lorenz \& Stark 2015, Kohsaka et al. 2017, Stange et al. 354 2017). Therefore, density of bee colonies held in urban areas has dramatically increased 355 and may favor the spread of diseases or pathogens (Youngsteadt et al. 2015). However, 
356 following this trend also bears the risk of a higher exposure to RF-EMF emission, which 357 seems to be continuously increasing in major cities (Urbinello et al. 2014b), potentially

358 affecting bee health in a future scenario. It might also be worthy to look into parasite359 host-interactions of the honey bee, Varroa destructor in particular, where a disturbance 360 through RF-EMF in host-finding could actually be a benefit (Frey et al. 2013).

361 Surprisingly, not many studies are available that are investigating the influence of such

362 irradiation on bees and other important pollinators. It has even been suggested to create

363 pollinator reservoirs beneath power corridors for an optimal land use and as a benefit for 364 many insects (Russel et al. 2018). Yet, it remains unclear to what extend 365 electromagnetic fields can possibly influence these microenvironments.

\section{Conclusion}

367 Even though detrimental effects on ontogenetic queen development were revealed by 368 the outcome of our study, caution is needed in interpreting these results. We have 369 created by far a worst case scenario to which honey bee colonies would not be exposed 370 under realistic conditions. Duration and level were similar to average human exposure 371 by the use of a mobile phone, but not to those present at an apiary, neither in rural nor in 372 urban areas. And yet, queens that survived the treatment were able to establish full 373 functional colonies, demonstrating an immense recovering potential. Therefore we do 374 not assume any acute negative effects on bee health in the mid-term. However, we do 375 not rule out an influence through lower doses of permanent irradiation, in particular on a 376 chronic sublethal level. Hence, we urgently suggest further research should be carried 377 out in the long-term to ascertain what impacts are to be expected. 


\section{ACKNOWLEDGEMENTS}

382 Many thanks to Simon Hummel for providing adequate breeding lines to conduct

383 research with extremely calm honey bees.

384 This research did not receive any specific grant from funding agencies in the public,

385 commercial, or not-for-profit sectors.

386

387

Declarations of interest: none.

388

389 Ethical approval: This article does not contain any studies with human participants or

390 animals performed by any of the authors.

391

392

393 


\section{REFERENCES}

397 Akter H, Khan SA (2014) Sensitivity of Immature Stages of Dengue Causing Mosquito,

398 Aedes aegypti (L.) to Gamma Radiation. J Entomol 11:56-67. doi: $399 \quad 10.3923 /$ je.2014.56.67

400 Balmori A (2009) Electromagnetic pollution from phone masts. Effects on wildlife.

401 Pathophysiology 16:191-199. doi: 10.1016/j.pathophys.2009.01.007

402 Balmori A (2015) Anthropogenic radiofrequency electromagnetic fields as an emerging 403 threat to wildlife orientation. Sci Total Environ 518-519:58-60. doi: 10.1016/j.scitotenv.2015.02.077

405 Bastide M, Youbicier-Simo BJ, Lebecq JC, Giaimis J. (2001) Toxicological study of 406 electromagnetic radiation emitted by television and video display screens and cellular 407 telephones on chickens and mice. Indoor Built Environ;10:291-8.

408 Batellier F, Couty I, Picard D, Brillard JP (2008) Effects of exposing chicken eggs to a 409 cell phone in 'call' position over the entire incubation period. Theriogenology;69: 73741045.

411 Carreck N (2014) Electromagnetic Radiation and Bees, Again... Bee World 91:4, 101412 102. doi: : 10.1080/0005772X.2014.11417624

413 Clarke D, Whitney H, Sutton G, Robert D (2013) Detection and Learning of Floral 414 Electric Fields by Bumblebees. Science (80- ) 340:66-69. doi: 10.1126/science.1230883

415 Core A, Runckel C, Ivers J, Quock C, Siapno T, DeNault S, Brown B, DeRisi J, Smith 416 CD, Hafernik J (2012) A New Threat to Honey Bees, the Parasitic Phorid Fly 417 Apocephalus borealis. PLoS One 7:e29639. doi: 10.1371/journal.pone.0029639

418 Cucurachi S, Tamis WLM, Vijver MG, Peijnenburg WJGM, Bolte JFB, de Snoo GR 419 (2013) A review of the ecological effects of radiofrequency electromagnetic fields (RF420 EMF). Environ Int 51:116-140. doi: 10.1016/j.envint.2012.10.009 
421 Dalio, J. S. (2015) Effect of electromagnetic (cell phone) radiations on Apis mellifera,

422 Journal of Res in Agriculture and Animal science 2(12): 06-10.

423 Deutscher Wetterdienst DWD (2018) Deutschlandwetter im Sommer 2018 424 Pressemitteilung. www.dwd.de, Accessed 26 September 2018

425 Eouzan I, Garnery L, Pinto MA, Delalande D, Neves CJ (2018) Hygroregulation , a key 426 ability for eusocial insects : Native Western European bees as a case study. bioRxiv. 427 doi: $10.1101 / 351874$

428 Favre D (2011) Mobile phone-induced honeybee worker piping. Apidologie 42:270429 279. doi: 10.1007/s13592-011-0016-x

430 Federal Network Agency (2011) Press Release 28 July 2011: Average duration of 2.5 431 minutes for mobile calls, Bonn, Germany, http:// www.bundesnetzagentur.de, Accessed $432 \quad 24$ August 2018

433 Ferrari TE (2014) Magnets, magnetic field fluctuations and geomagnetic disturbances 434 impair the homing ability of honey bees (Apis mellifera ). J Apic Res 53:452-465. doi: $435 \quad$ 10.3896/IBRA.1.53.4.15

436 Frei P, Mohler E, Neubauer G, Theis G, Bürgi A, Fröhlich J, Braun-Fahrländer C, Bolte 437 J, Egger M, Röösli M (2009) Temporal and spatial variability of personal exposure to 438 radio frequency electromagnetic fields. Environ Res 109:779-785. doi: $439 \quad 10.1016 /$ j.envres.2009.04.015

440 Frey E, Odemer R, Blum T, Rosenkranz P (2013) Activation and interruption of the 441 reproduction of Varroa destructor is triggered by host signals (Apis mellifera). J 442 Invertebr Pathol 113:56-62. doi: 10.1016/j.jip.2013.01.007

443 Friebel G, Seabright P (2011) Do women have longer conversations? Telephone 444 evidence of gendered communication strategies. J Econ Psychol 32:348-356. doi: $445 \quad$ 10.1016/j.joep.2010.12.008

446 Gallai N, Salles JM, Settele J, Vaissière BE (2009) Economic valuation of the 447 vulnerability of world agriculture confronted with pollinator decline. Ecol Econ 68:810448 821. doi: 10.1016/j.ecolecon.2008.06.014 
449 Genuis SJ, Lipp CT (2012) Electromagnetic hypersensitivity: Fact or fiction? Sci Total

450 Environ 414:103-112. doi: 10.1016/j.scitotenv.2011.11.008

451 Girling RD, Lusebrink I, Farthing E, Newman TA, Poppy GM (2013) Diesel exhaust

452 rapidly degrades floral odours used by honeybees. Sci Rep 3:2779. doi: $453 \quad 10.1038 /$ srep02779

454 Grigoryev Y. (2003) Biological effects of mobile phone electromagnetic field on chick 455 embryo (risk assessment using the mortality rate). Radiats Biol Radioecol;43:541-3

456 Gullan P.J., Cranston P.S. (2014) The Insects: An Outline of Entomology, Fifth Edition, 457 John Wiley \& Sons Blackwell, Oxford ISBN: 1-4051-1113-5

458 Hardell L (2017) World Health Organization, radiofrequency radiation and health - a 459 hard nut to crack (Review). Int J Oncol 51:405-413. doi: 10.3892/ijo.2017.4046

460 Imdorf A, Buehlmann G, Gerig L, Kilchenmann V (1987) Überprüfung der 461 Schätzmethode zur Ermittlung der Brutfläche und der Anzahl Arbeiterinnen in 462 freifliegenden Bienenvölkern. Apidologie 18:137-146. doi: 463 http://dx.doi.org/10.1051/apido:19870204

464 Johnson JA (1987) Sensitivity of Larvae, Pupae, and Adults of the Driedfruit Beetle 465 (Coleoptera : Nitidulidae) to Gamma Radiation. J Econ Entomol 80:1302-1305.

466 Kimmel S, Kuhn J, Harst W, Stever H (2007) Electromagnetic Radiation : Influences on 467 Honeybees (Apis mellifera ), unpublished 1-6.

468 Kohsaka R, Park MS, Uchiyama Y (2017) Beekeeping and honey production in Japan 469 and South Korea: past and present. J Ethn Foods 4:72-79. doi: $470 \quad 10.1016 /$ j.jef.2017.05.002

471 Kumar NR, Sangwan S, Badotra P. (2011) Exposure to cell phone radiations produces 472 biochemical changes in worker honey bees. Toxicol Int;18(1):70-2.

473 Lautenbach S, Seppelt R, Liebscher J, Dormann CF (2012) Spatial and temporal trends 474 of global pollination benefit. PLoS One. doi: 10.1371/journal.pone.0035954 
475 Le Conte Y, Navajas M (2008) Climate change: impact on honey bee populations and 476 diseases. Rev Sci Tech 27:485-97, 499-510.

477 Lenhart A (2010) Cell phones and American adults: They make just as many calls, but 478 text less often than teens. Pew Res Cent 1-42.

479 Lorenz S, Stark K (2015) Saving the honeybees in Berlin? A case study of the urban 480 beekeeping boom, Environmental Sociology, 1:2, 116-126, DOI: $481 \quad 10.1080 / 23251042.2015 .1008383$

482 Margaritis LH, Manta AK, Kokkaliaris KD, Schiza D, Alimisis K, Barkas G, Georgiou 483 E, Giannakopoulou O, Kollia I, Kontogianni G, Kourouzidou A, Myari A, Roumelioti 484 F, Skouroliakou A, Sykioti V, Varda G, Xenos K, Ziomas K (2014) Drosophila 485 oogenesis as a bio-marker responding to EMF sources. Electromagn Biol Med 33:165486 89. doi: $10.3109 / 15368378.2013 .800102$

487 McFrederick QS, Kathilankal JC, Fuentes JD (2008) Air pollution modifies floral scent 488 trails. Atmos Environ 42:2336-2348. doi: 10.1016/j.atmosenv.2007.12.033

489 Milivojević T, Glavan G, Božič J, Sepčić K, Mesarič T, Drobne D (2015) Neurotoxic 490 potential of ingested $\mathrm{ZnO}$ nanomaterials on bees. Chemosphere 120:547-554. doi: $491 \quad 10.1016 / j . c h e m o s p h e r e .2014 .07 .054$

492 Moore P, Wilson ME, Skinner JA (2015) Honey Bee Queens: Evaluating the Most 493 Important Colony Member, Department of Entomology and Plant Pathology, The 494 University of Tennessee, Knoxville TN, www.extension.org, Accessed 26 September $495 \quad 2018$

496 Panagopoulos DJ (2012) Effect of Microwave Exposure on the Ovarian Development of 497 Drosophila melanogaster. Cell Biochem Biophys 63:121-132. doi: 10.1007/s12013$498 \quad 012-9347-0$

499 Panagopoulos DJ, Cammaerts M-C, Favre D, Balmori A (2016) Comments on 500 environmental impact of radiofrequency fields from mobile phone base stations. Crit 501 Rev Environ Sci Technol 46:885-903. doi: 10.1080/10643389.2016.1182107 
502 Panagopoulos DJ, Chavdoula ED, Karabarbounis A, Margaritis LH (2007) Comparison

503 of bioactivity between GSM $900 \mathrm{MHz}$ and DCS $1800 \mathrm{MHz}$ mobile telephony radiation.

504 Electromagn Biol Med 26:33-44. doi: 10.1080/15368370701205644

505 Panagopoulos DJ, Chavdoula ED, Margaritis LH (2010) Bioeffects of mobile telephony 506 radiation in relation to its intensity or distance from the antenna. Int $\mathrm{J}$ Radiat Biol 86:345-357. doi: 10.3109/09553000903567961

508 Panagopoulos DJ, Johansson O, Carlo GL (2015) Real versus simulated mobile phone exposures in experimental studies. Biomed Res Int. doi: 10.1155/2015/607053

510 Panagopoulos DJ, Karabarbounis A, Margaritis LH (2004) Effect of GSM 900-MHz

511 mobile phone radiation on the reproductive capacity of Drosophila melanogaster.

512 Electromagn Biol Med 23:29-43. doi: 10.1081/JBC-120039350

513 Panagopoulos DJ, Margaritis LH (2010) The effect of exposure duration on the

514 biological activity of mobile telephony radiation. Mutat Res - Genet Toxicol Environ

515 Mutagen 699:17-22. doi: 10.1016/j.mrgentox.2010.04.010

516 R Core Team (2018) R: A language and environment for statistical computing. R

517 Foundation for Statistical Computing, Vienna, Austria.

518 Roberts J, Yaya L, Manolis C (2014) The invisible addiction: Cell-phone activities and

519 addiction among male and female college students. J Behav Addict 3:254-265. doi:

$520 \quad 10.1556 /$ JBA.3.2014.015

521 Roux, D., Vian, A., Girard, S., Bonnet, P., Paladian, F., Davies, E., and Ledoigt, G.

522 (2006). Electromagnetic fields $(900 \mathrm{MHz})$ evoke consistent molecular responses in 523 tomato plants. Physiologia Plantarum, 128, 283-288.

524 Roux, D., Vian, A., Girard, S., Bonnet, P., Paladian, F., Davies, E., and Ledoigt, G. 525 (2008). High frequency (900 MHz) low amplitude $\left(5 \mathrm{~V} \mathrm{~m}_{i} 1\right)$ electromagnetic field: A 526 genuine environmental stimulus that affects transcription, translation, calcium and 527 energy charge in tomato. Planta, 227, 883-891.

528 Russell KN, Russell GJ, Kaplan KL, Mian S, Kornbluth S (2018) Increasing the 529 conservation value of powerline corridors for wild bees through vegetation 
530 management: an experimental approach. Biodivers Conserv 27:2541-2565. doi: $531 \quad 10.1007 / \mathrm{s} 10531-018-1552-8$

532 Sagar S, Struchen B, Finta V, Eeftens M, Röösli M (2016) Use of portable exposimeters 533 to monitor radiofrequency electromagnetic field exposure in the everyday environment.

534 Environ Res 150:289-298. doi: 10.1016/j.envres.2016.06.020

535 Sahib, S. (2011). Electromagnetic radiation (EMR) clashes with honey bees. 536 International Journal of Environmental Sciences 1, 897-900.

537 Sharma MC, Kumar N (2010) Changes in honeybee behaviour and biology under the

538 influence of cellphone radiations. Vet Parasitol 154:98-102. doi: 539 10.1016/j.vetpar.2008.03.001

540 Shum M, Kelsh MA, Sheppard AR, Zhao K (2011) An evaluation of self-reported 541 mobile phone use compared to billing records among a group of engineers and 542 scientists. Bioelectromagnetics 32:37-48. doi: 10.1002/bem.20613

543 Smart M, Pettis J, Rice N, Browning Z, Spivak M (2016) Linking Measures of Colony 544 and Individual Honey Bee Health to Survival among Apiaries Exposed to Varying 545 Agricultural Land Use. PLoS One 11:e0152685. doi: 10.1371/journal.pone.0152685

546 Stange E, Zulian G, Rusch G, Barton D, Nowell M (2017) Ecosystem services mapping 547 for municipal policy: ESTIMAP and zoning for urban beekeeping. One Ecosyst $548 \quad$ 2:e14014. doi: 10.3897/oneeco.2.e14014

549 Steinhauer N, Kulhanek K, Antúnez K, Human H, Chantawannakul P, Chauzat M-P, 550 VanEngelsdorp D (2018) Drivers of colony losses. Curr Opin Insect Sci 26:142-148. 551 doi: $10.1016 /$ j.cois. 2018.02 .004

552 Straub L, Williams GR, Pettis J, Fries I, Neumann P (2015) Superorganism resilience: 553 eusociality and susceptibility of ecosystem service providing insects to stressors. Curr 554 Opin Insect Sci 12:109-112. doi: 10.1016/j.cois.2015.10.010

555 Urbinello D, Joseph W, Huss A, Verloock L, Beekhuizen J, Vermeulen R, Martens L, 556 Röösli M (2014) Radio-frequency electromagnetic field (RF-EMF) exposure levels in 
557 different European outdoor urban environments in comparison with regulatory limits.

558 Environ Int 68:49-54. doi: 10.1016/j.envint.2014.03.007

559 Urbinello D, Joseph W, Verloock L, Martens L, Röösli M (2014) Temporal trends of

560 radio-frequency electromagnetic field (RF-EMF) exposure in everyday environments

561 across European cities. Environ Res 134:134-142. doi: 10.1016/j.envres.2014.07.003

562 Vacha M, Puzova T, Kvicalova M (2009) Radio frequency magnetic fields disrupt

563 magnetoreception in American cockroach. J Exp Biol 212:3473-3477. doi: $564 \quad 10.1242 /$ jeb.028670

565 van Engelsdorp D, Hayes J, Underwood RM, Pettis J (2008) A survey of honey bee 566 colony losses in the U.S., Fall 2007 to Spring 2008. PLoS One 3:8-13. doi: 567 10.1371/journal.pone.0004071

568 Vanengelsdorp D, Evans JD, Saegerman C, Mullin C, Haubruge E, Nguyen BK, Frazier

569 M, Frazier J, Cox-Foster D, Chen Y, Underwood R, Tarpy DR, Pettis JS (2009) Colony

570 collapse disorder: a descriptive study. PLoS One 4:e6481. doi:

$571 \quad 10.1371$ journal.pone.0006481

572 Verschaeve L (2014) Environmental Impact of Radiofrequency Fields from Mobile

573 Phone Base Stations. Crit Rev Environ Sci Technol 44:1313-1369. doi: $10.1080 / 10643389.2013 .781935$

575 Vilić M, Tlak Gajger I, Tucak P, Štambuk A, Šrut M, Klobučar G, Malarić K, Žura Žaja

576 I, Pavelić A, Manger M, Tkalec M (2017) Effects of short-term exposure to mobile 577 phone radiofrequency $(900 \mathrm{MHz})$ on the oxidative response and genotoxicity in honey 578 bee larvae. J Apic Res 56:430-438. doi: 10.1080/00218839.2017.1329798

579 Waldmann-Selsam C, Balmori-de la Puente A, Breunig H, Balmori A (2016) 580 Radiofrequency radiation injures trees around mobile phone base stations. Sci Total 581 Environ 572:554-569. doi: 10.1016/j.scitotenv.2016.08.045

582 Wang Y, Ma L-T, Xu B-H (2015) Diversity in life history of queen and worker honey 583 bees, Apis mellifera L. J Asia Pac Entomol 18:145-149. doi: 
585 Weisbrot D, Lin H, Ye L, Blank M, Goodman R (2003) Effects of mobile phone

586 radiation on reproduction and development in Drosophila melanogaster. J Cell

587 Biochem;89: 48-55

588 World Health Organization WHO (2014) Electromagnetic fields and public health:

589 mobile phones, www.who.int, Accessed 16 August 2018

590 Youngsteadt E, Appler RH, López-Uribe MM, Tarpy DR, Frank SD (2015)

591 Urbanization increases pathogen pressure on feral and managed honey bees. PLoS One.

592 doi: 10.1371/journal.pone.0142031 